\title{
Efficacy of graded activity versus supervised exercises in patients with chronic non-specific low back pain: protocol of a randomised controlled trial
}

Mauricio Oliveira Magalhaes*, Fábio Jorge Renovato França, Thomaz Nogueira Burke, Luiz Armando Vidal Ramos, Ana Paula de Moura Campos Carvalho e Silva, Gabriel Peixoto Leao Almeida, Susan Lee King Yuan and Amélia Pasqual Marques

\begin{abstract}
Background: Low back pain is a relevant public health problem, being an important cause of work absenteeism worldwide, as well as affecting the quality of life of sufferers and their individual functional performances. Supervised active physical routines and of cognitive-behavioral therapies are recommended for the treatment of chronic Low back pain, although evidence to support the effectiveness of different techniques is missing. Accordingly, the aim of this study is to contrast the effectiveness of two types of exercises, graded activity or supervised, in decreasing symptoms of chronic low back pain.

Methods/design: Sample will consist of 66 patients, blindly allocated into one of two groups: 1) Graded activity which, based on an operant approach, will use time-contingent methods aiming to increase participants' activity levels; 2) Supervised exercise, where participants will be trained for strengthening, stretching, and motor control targeting different muscle groups. Interventions will last one hour, and will happen twice a week for 6 weeks. Outcomes (pain, disability, quality of life, global perceived effect, return to work, physical activity, physical capacity, and kinesiophobia) will be assessed at baseline, at treatment end, and three and six months after treatment end. Data collection will be conducted by an investigator blinded to treatment allocation.

Discussion: This project describes the randomisation method that will be used to compare the effectiveness of two different treatments for chronic low back pain: graded activity and supervised exercises. Since optimal approach for patients with chronic back pain have yet not been defined based on evidence, good quality studies on the subject are necessary.
\end{abstract}

Trial registration: NCT01719276

\section{Background}

Low back pain (LBP) is a relevant public health problem, being an important cause of work absenteeism worldwide [1-3], as well as affecting sufferers' quality of life [1] and individual functional performances [1]. Non-specific chronic LBP (cLBP), which does not have a well-defined etiology and presents pain for at least 12 consecutive weeks, represents up to $95 \%$ of the cases of LBP [1]. The

\footnotetext{
*Correspondence: m.magalhaes@usp.br

Department of Physical Therapy, Communication Science \& Disorders,

Occupational Therapy, University of São Paulo, São Paulo, Brazil
}

annual direct costs of cLBP in the United States range from 12.2 to 90.6 billions of dollars, and represent only $14.5 \%$ of the total costs of this health condition [4]. Lifetime prevalence of cLBP ranges from 11 to $84 \%$; 1-year prevalence ranges from $22 \%$ to $65 \%$, and point-prevalence from $12 \%$ to $33 \%$ [5].

The European Guidelines recommends the use of supervised active exercises, manipulation/mobilization, Back Schools, multidisciplinary approaches and cognitive-behavioral therapies for patients with cLBP [1]. Evidence suggests that 
supervised exercise and cognitive behavioral therapies improve pain and reduce functional disability [6].

Strengthening exercises for abdominal and trunk muscles, motor control exercises for lumbar multifidus (LM) and transversus abdominis (TrA) and stretching exercises for trunk and lower limbs show some evidence of improvement of pain and functional disability in individuals with cLBP $[1,7,8]$. Strengthening exercises of abdominal and trunk muscles are based on the known association between weakness of the trunk and abdomen muscles and low back pain [9-14]. Weakness is a consequence of sedentary life, and is associated to paravertebral muscle hypotrophy [14] and changes in motor control [15]. Furthermore, deep muscles of the abdomen and trunk such as the TrA and LM are also affected in patients with cLBP [16]. Some studies have focused on the individual use of muscle stretching and strengthening or motor control in cLBP $[17,18]$. However, Macedo and colleagues [19], on their systematic review, recommend motor control exercises associated with other types of exercise.

Cognitive behavioral therapy uses brief interventions and counseling strategies in order to facilitate behavioral changes [20], by modifying negative attitudes and beliefs [21]. The "Back Book" [22] may be used as a good educational support, since it offers evidence-based information that is consistent with biopsychosocial models. Cognitive-behavioral programs that showed some evidence for use in patients with cLBP include the Back Skills Training program (BeST) [21,23], Brief Intervention (BI) [24,25] and the Graded Activity [26].

The Graded Activity program, which was initially developed by Lindstrõm et al. [27], recommends the use of an individualized and submaximal exercise program, with educational support in order to enhance self-trust and tolerance to effort. Although it has been suggested that graded activity is effective in decreasing pain and functional disability in cLBP [26,28], van der Giessen (2012), in a systematic review [29], concluded that there is insufficient evidence on the effects of graded activity in pain, disability and return to work in patients with non-specific cLBP. Furthermore, the Clinical Practice Guidelines Linked to the International Classification of Functioning, Disability, and Health from the Orthopaedic Section of the American Physical Therapy Association [3] states that effectiveness of cognitive behavioral therapy in CLBP is moderate.

The literature is not clear regarding which exercise programs are most effective for patients with cLBP; therefore, more randomised controlled trials are necessary to clarify these questions. Moreover, little is known about the effect of graded activity compared with supervised exercise program (strengthening, stretching and motor control) in patients with non-specific cLBP.

\section{Study aim}

The aim of this paper is to report the study protocol used to investigate the effect of two types of exercise program in reducing the symptoms of non-specific cLBP.

\section{Methods and design}

The study will be a randomised controlled trial comparing graded activity with a supervised exercise program in patients with non-specific cLBP. Each treatment program will consist of 12 individually supervised 1-hour sessions over a six-week period.

\section{Enrollment and eligibility criteria}

A total of 66 patients will be recruited at the Rehabilitation Center of Taboao da Serra, Brazil.

\section{Inclusion criteria}

- Non-specific cLBP;

- Age between 18 and 65 years;

- A minimum pain intensity score of three in the 11point Pain Numerical Rating Scale [24].

\section{Exclusion criteria}

- Known or suspected serious spinal pathology (fractures, tumors, inflammatory or infective diseases of the spine);

- Nerve root compromise;

- Comorbid health conditions that would prevent active participation in the exercise programs;

- Pregnancy;

- Cardio-respiratory illnesses.

In order to ensure patients' safe participation in the study, the Physical Activity Readiness Questionnaire (PAR-Q) will be used [30]. Those answering "yes" to any of the questions will be excluded.

\section{Procedures}

All measurements will be conducted by a physical therapist blinded to patients' groups. The investigator will confirm the eligibility criteria, as well as obtain demographic (civil status, education, tabagism and use of medication) and anthropometric data (age, height, weight and body mass index). Past treatments and use of medication for cLBP will also be recorded. The investigator will also assess primary (pain severity and functional disability) and secondary outcomes (quality of life, global perceived effect, return to work, physical activity, physical capacity and kinesiophobia). Patients will be assessed at baseline, immediately after the treatment and at three and sixmonth follow-up. 


\section{Randomisation procedures}

Before treatment onset, the patients will be randomly allocated into one of two groups: Graded Activity (GA) or Supervised Exercise (SE), through a computer-generated randomisation schedule that will be performed by an independent researcher, not involved in other study procedures. The allocation of participants will be concealed by using consecutive numbered, sealed and opaque envelopes [31]. The flow of the study is summarized in Figure 1.

\section{Outcome measures}

All instruments were used in their translated and adapted to Brazilian-Portuguese versions, with adequate psychometrical properties [24,25,32-34]. Pain, functional disability, return to work, physical activity, physical capacity and kinesiophobia will be measured.

\section{Primary outcomes}

Pain

Pain will be assessed quantitatively and qualitatively with the Numerical Rating Scale (NRS) and the McGill Pain Questionnaire. The NRS is an 11-point scale ranging from 0 to 10, in which 0 defines absence of pain and 10 describes unbearable pain [24]. Participants will be asked to rate the average pain levels over the week before assessment [24].

The McGill Pain Questionnaire provides a multidimensional assessment of pain. It consists of 78 descriptors of the quantity and quality of pain which are grouped in four

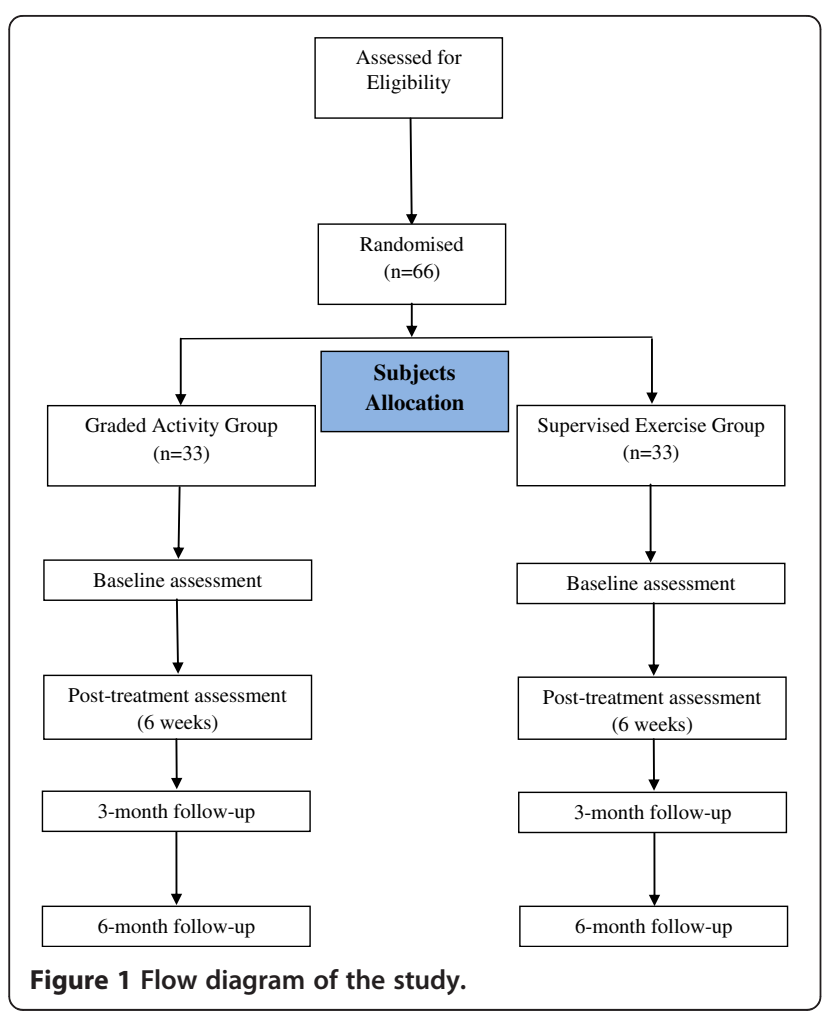

major domains (sensory, affective, evaluative and miscellanea) and 20 sub-domains with 1 to 5 descriptors each, to which intensity values are assigned. The questionnaire is used to describe pain experience and the score corresponds to the sum of the aggregated values. Maximal scores will be: Sensorial $=41$, Affective $=14$, Evaluative $=5$, Miscellanea $=17$, Total $=7[35]$.

\section{Functional disability}

The Roland Morris Disability Questionnaire will be used to assess functional disability due to LBP. It consists of 24 questions focusing on normal activities of daily life. Each affirmative answer corresponds to 1 point and the final score is determined by the total number of points. Total score ranges from 0 to 24 and higher scores reflect increased disability. Scores above 14 reflect severe impairment $[24,25,36]$.

\section{Secondary outcomes \\ Quality of life}

Short-Form Health Survey Questionnaire (SF-36) assesses health-related qualify of life. It consists of 36 questions grouped in eight domains: vitality (4 items), Physical Functioning (10 items), Bodily Pain (2 items), General Health (5 items), Physical Role (2 items), Emotional Role (3 items), Social Functioning (2 items) and Mental Health (5 items). For each domain, scores range from 0 to 100 and higher scores reflect better quality of life. Only the physical and emotional domains will be used [32].

\section{Global perceived effect}

The Global Perceived Effect Scale is an 11-point scale that ranges from -5 (vastly worse), zero (no change) to +5 (completely recovered). For all of the measures of perceived global effect, the participants will be asked the following question: "Compared to when this episode first started, how would you describe your back?" Positive scores represent greater recovery and negative scores represent worsening of the symptoms [24].

\section{Return to work}

The evaluation will be made by questioning if the patient is off work due to back pain and the positive or negative response will be recorded.

\section{Kinesiophobia}

The Tampa Scale of Kinesophobia (TSK) is a self-applied questionnaire consisting of 17 items, which was developed to measure the fear of movement due to cLBP. Each question has 4 response options (strongly disagree, disagree, agree, and strongly agree) with scores respectively ranging from 1 to 4 points. The scores of items 4, 8, 12 and 16 are inverted and the total score is the sum of the items, which 
Table 1 Description of the protocol of the Supervised Exercise Group

\begin{tabular}{|c|c|c|}
\hline Exercise & Position & Sets/Duration \\
\hline \multirow[t]{4}{*}{ Stretching } & Stretching of the erector spinae in dorsal decubitus, with flexed hips and knees; & 3 sets of 30 seconds \\
\hline & $\begin{array}{l}\text { Stretching of the hamstrings and triceps surae in dorsal decubitus, with forced flexion of } 1 \text { limb at a } \\
\text { time with assistance of the physical therapist; }\end{array}$ & \\
\hline & $\begin{array}{l}\text { Stretching of the erector spinae with the patient sitting on heels, flexed trunk with the abdomen } \\
\text { resting on the front of the thighs; }\end{array}$ & $\begin{array}{l}\text { Intervals between series of } \\
30 \text { seconds }\end{array}$ \\
\hline & $\begin{array}{l}\text { Global stretching of the posterior muscular chain (erector spinae, hamstring, triceps surae.) } 2 \text { series of } \\
\qquad 4 \text { minutes were performed, with } 1 \text { minute of resting interval. }\end{array}$ & \\
\hline \multirow[t]{4}{*}{ Strengthening } & Exercises for the rectus abdominis in dorsal decubitus with flexed knees: trunk flexion; & 2 sets of 12 repetitions \\
\hline & $\begin{array}{l}\text { Exercises for the rectus abdominis, external and internal obliquus in dorsal decubitus and flexed knees: } \\
\text { trunk flexion and rotation; }\end{array}$ & \\
\hline & Exercises for the rectus abdominis in dorsal decubitus and semi-flexed knees: hip flexion; & between series of \\
\hline & Exercises for the erector spinae in ventral decubitus: trunk extension. & \\
\hline \multirow[t]{4}{*}{ Motor control } & Exercises for the lumbar multifidus in ventral decubitus; & 2 sets of 10 repetitions \\
\hline & Exercises for the transversus abdominis muscle in dorsal decubitus with flexed knees; & \\
\hline & Exercises for the transversus abdominis muscle in 4 point kneeling; & \multirow{2}{*}{$\begin{array}{l}\text { Intervals between series of } \\
30 \text { seconds }\end{array}$} \\
\hline & Co-contraction of the transversus abdominis muscle and lumbar multifidus in the upright position. & \\
\hline
\end{tabular}

ranges from 17 to 68 points. Increased values reflect increased fear of movement $[37,38]$.

\section{Physical activity}

The Baecke Physicial Activity Questionnaire measures physical activity in three domains: occupational activity, physical exercises and leisure/locomotion. It consists of 16 questions structured as a quantitative Likert scale. Its score is determined by the sum of the domain scores. Physical activity may be classified as mild (3.0-6.7), moderate (6.8-8.1) or intense (8.2-15.0) [34].

\section{Physical capacity}

The sit-to-stand and $15.24 \mathrm{~m}$ walk tests will be used. Five repetitions of the sit-to-stand test will be performed at maximal speed, without using the hands [39]. After five minutes of rest, the walk test will be performed, in which patients walk through $7.62 \mathrm{~m}$, turn around and return to the initial position. The sit-to-stand and walk test will be assessed twice with an interval of three minutes, and the average value will be used for analyses [39]. Time will be measured using a digital manual stopwatch (instrutherm ${ }^{\circledR}$ ).

\section{0-repetition maximum test (10-RM)}

The 10-RM test measures the maximal load that allows participants to perform 10 complete repetitions. This test will be used for the flexor and extensor muscles of the knee. The progressive method will be used, beginning with smaller loads that will be progressively increased until participants can no longer generate the torque required for completing 10 repetitions. In-between each series, individuals will rest for 1 minute.

During the first two weeks of training, individuals will exercise using $50 \%$ of the maximum load. On the third and fourth week, the load will be $60 \%$ of maximum; for the final two weeks, it will be $70 \%$ [40].

\section{Intervention}

Interventions will last 60 minutes and will happen twice a week for 6 weeks. They will be supervised by the investigator and participants will be asked to report any complaint (adverse events) related or not to treatment. They will also be instructed not to initiate any intervention while during the study. Ongoing medications will be maintained.

Table 2 Description of the protocol of the Graded Activity Group

\begin{tabular}{ccc}
\hline Exercise & Position & Sets/Duration \\
\hline Aerobic training on the treadmill & 5-minute warm-up with speed of 5-8 km/h; \\
20-minute submaximal training at 70-80\% maximum heart rate; & 5-minute slow-down with gradual speed reduction. \\
Lower limbs strengthening & Exercise for the quadriceps in sitting position; & 3 sets of 12 repetitions for each limb \\
Trunk strengthening & Exercises for the erector spinae in ventral decubitus: trunk extension. & 3 sets of 10 repetitions \\
& Intervals between series of 30 seconds
\end{tabular}




\section{Supervised exercise program}

Patients in the Supervised Exercise Group will perform stretching, strengthening and motor control exercises, as described in Table 1.

\section{Graded activity}

For this group, we will follow the protocols described by Macedo et al. [41] and Smeets et al. [42], which are based on individualized, progressive and sub-maximal exercises aiming to improve physical fitness and stimulate changes in behavior and attitudes due to pain. Positive reinforcement will be provided during the sessions ("you are doing great", "congratulations", "keep up with the good work", "you can make it"), with the aim of maintaining the motivation.

In the beginning of the treatment, patients will select one or two activities considered difficult to them and receive guidance concerning them throughout the treatment, with the establishment of weekly goals. Participants will also receive an educational material (based on "Back Book"), with the purpose of providing important information about how to care for the spine. Weekly reading goals of the educational material will also be defined and the topics will be discussed at the end of each week. The protocol is described in Table 2 .

Heart rate (HR) will be calculated using the formula of Karvonen (maximum HR $=200$ - age) for sedentary individuals: Exercise $\mathrm{HR}=$ Resting $\mathrm{HR}+70 \%$ to $80 \%$ of maximum HR [43].

\section{Sample size calculation}

Sample size was defined in order to detect a 2-point difference between groups on the pain intensity outcome measured by the Pain Numerical Rating Scale, assuming a standard deviation of 1.9 points [24]. We also sought power to detect a 4-point difference in functional disability measured by the Roland Morris Disability Questionnaire, with an estimated standard deviation of 4.9 points $[24,25,36]$. Power was defined as $80 \%$ for an alpha of $5 \%$ and attrition (drop-outs) of 15\%. Accordingly, 33 participants per group will be needed.

\section{Statistical analyses}

All of the statistical analysis will be based on intentionto-treat basis [44]. We will use linear mixed models to test for treatment effects between groups at the end of the treatment and at three and six-month follow-up. Treatment effect sizes will be calculated for each time points, as well as statistical significance. Analyses will be conducted using SPSS 19 and SigmaPlot 10. A level of significance of $5 \%$ will be used.

\section{Ethics and data security}

This trial was approved by the Ethics Committee of the School of Medicine of the University of Sao Paulo (protocol study-052826/2012). All patients will be asked to provide written, informed consent prior to randomisation, using standard forms. Data access and storage will be kept in accordance to the National Health and Medical Research Council guidelines. This trial is registered in ClinicalTrials.gov (a service of U.S. National Institutes of Health) under the number NCT01719276.

\section{Discussion}

The purpose of this randomised controlled trial is to compare the effect of graded activity and supervised exercise in patients with non-specific cLBP. The study will contribute to clinical practice by providing evidence to guide decisions for the proper treatment of patients with cLBP. The results of this study will be published once the study is concluded.

\section{Competing interests}

The authors declare that they have no competing interests.

\section{Authors' contributions}

MOM, FJR, LAVR, TNB, APMCCS, GPLA, SLKY were responsible for the design of the study. APM will act as the study coordinators. All authors read and approved the final manuscript.

\section{Acknowledgements}

This study has Public Financial Support of: State of São Paulo Research Foundation (FAPESP), Brazil. Mauricio Oliveira Magalhães is a PhD student supported by an scholarship from the Fundação de Amparo a Pesquisa do Estado de São Paulo (FAPESP).

Received: 27 November 2012 Accepted: 7 January 2013

Published: 21 January 2013

\section{References}

1. Airaksinen O, Brox Jl, Cedraschi C, Hildebrandt J, Klaber-Moffett J, Kovacs F, Mannion AF, Reis S, Staal JB, Ursin H, Zanoli G: Chapter 4. European guidelines for the management of chronic nonspecific low back pain. Eur Spine J 2006, 15(Suppl 2):S192-S300.

2. Costa Lda C, Maher CG, McAuley JH, Hancock MJ, Herbert RD, Refshauge KM, Henschke N: Prognosis for patients with chronic low back pain: inception cohort study. BMJ 2009, 339:b3829.

3. Delitto A, George SZ, Van Dillen LR, Whitman JM, Sowa G, Shekelle P, Denninger TR, Godges JJ: Low back pain. J Orthop Sports Phys Ther 2012, 42:A1-A57.

4. Dagenais S, Caro J, Haldeman S: A systematic review of low back pain cost of illness studies in the United States and internationally. Spine J 2008, 8:8-20.

5. Walker BF: The prevalence of low back pain: a systematic review of the literature from 1966 to 1998. J Spinal Disord 2000, 13:205-217.

6. Koes BW, van Tulder MW, Thomas S: Diagnosis and treatment of low back pain. BMJ 2006, 332:1430-1434

7. Dufour N, Thamsborg G, Oefeldt A, Lundsgaard C, Stender S: Treatment of chronic low back pain: a randomized, clinical trial comparing groupbased multidisciplinary biopsychosocial rehabilitation and intensive individual therapist-assisted back muscle strengthening exercises. Spine (Phila Pa 1976) 2010, 35:469-476.

8. Smith C, Grimmer-Somers K: The treatment effect of exercise programmes for chronic low back pain. J Eval Clin Pract 2010, 16:484-491.

9. Okubo Y, Kaneoka K, Imai A, Shiina I, Tatsumura M, Izumi S, Miyakawa S: Electromyographic analysis of transversus abdominis and lumbar multifidus using wire electrodes during lumbar stabilization exercises. J Orthop Sports Phys Ther 2010, 40:743-750.

10. Bjerkefors A, Ekblom MM, Josefsson K, Thorstensson A: Deep and superficial abdominal muscle activation during trunk stabilization exercises with and without instruction to hollow. Man Ther 2010, 15:502-507. 
11. Barr KP, Griggs M, Cadby T: Lumbar stabilization: a review of core concepts and current literature, part 2. Am J Phys Med Rehabil 2007, 86:72-80.

12. Javadian $Y$, Behtash $H$, Akbari M, Taghipour-Darzi M, Zekavat $H$ : The effects of stabilizing exercises on pain and disability of patients with lumbar segmental instability. J Back Musculoskelet Rehabil 2012, 25:149-155.

13. Hodges PW, Moseley GL, Gabrielsson A, Gandevia SC: Experimental muscle pain changes feedforward postural responses of the trunk muscles. Exp Brain Res 2003, 151:262-271.

14. Danneels LA, Vanderstraeten GG, Cambier DC, Witvrouw EE, De Cuyper HJ: $\mathrm{CT}$ imaging of trunk muscles in chronic low back pain patients and healthy control subjects. Eur Spine J 2000, 9:266-272.

15. Hodges PW, Moseley GL: Pain and motor control of the lumbopelvic region: effect and possible mechanisms. J Electromyogr Kinesiol 2003, 13:361-370.

16. Hodges $P$, Richardson $C$, Jull G: Evaluation of the relationship between laboratory and clinical tests of transversus abdominis function. Physiother Res Int 1996, 1:30-40.

17. Franca FR, Burke TN, Caffaro RR, Ramos LA, Marques AP: Effects of muscular stretching and segmental stabilization on functional disability and pain in patients with chronic low back pain: a randomized, controlled trial. J Manipulative Physiol Ther 2012, 35:279-285.

18. Franca FR, Burke TN, Hanada ES, Marques AP: Segmental stabilization and muscular strengthening in chronic low back pain: a comparative study. Clinics (Sao Paulo) 2010, 65:1013-1017.

19. Macedo LG, Maher CG, Latimer J, McAuley JH: Motor control exercise for persistent, nonspecific low back pain: a systematic review. Phys Ther 2009, 89:9-25

20. Rundell SD, Davenport TE: Patient education based on principles of cognitive behavioral therapy for a patient with persistent low back pain: a case report. J Orthop Sports Phys Ther 2010, 40:494-501.

21. Lamb SE, Lall R, Hansen Z, Castelnuovo E, Withers EJ, Nichols V, Griffiths F, Potter R, Szczepura A, Underwood M: A multicentred randomised controlled trial of a primary care-based cognitive behavioural programme for low back pain. The Back Skills Training (BeST) trial. Health Technol Assess 2010, 14:1-253. iii-iv.

22. Roland M, Waddell G, Klaber-Moffett J, Burton AK, Main CJ, Cantrell T: The Back Book. Norwich: Stationery Office. United Kingdom; 1996.

23. Lamb SE, Hansen Z, Lall R, Castelnuovo E, Withers EJ, Nichols V, Potter R, Underwood MR: Group cognitive behavioural treatment for low-back pain in primary care: a randomised controlled trial and costeffectiveness analysis. Lancet 2010, 375:916-923.

24. Costa LO, Maher CG, Latimer J, Ferreira PH, Ferreira ML, Pozzi GC, Freitas LM: Clinimetric testing of three self-report outcome measures for low back pain patients in Brazil: which one is the best? Spine (Phila Pa 1976) 2008, 33:2459-2463

25. Nusbaum L, Natour J, Ferraz MB, Goldenberg J: Translation, adaptation and validation of the Roland-Morris questionnaire-Brazil Roland-Morris. Braz $J$ Med Biol Res 2001, 34:203-210.

26. Macedo LG, Latimer J, Maher CG, Hodges PW, McAuley JH, Nicholas MK, Tonkin L, Stanton CJ, Stanton TR, Stafford R: Effect of motor control exercises versus graded activity in patients with chronic nonspecific low back pain: a randomized controlled trial. Phys Ther 2012, 92:363-377.

27. Lindstrom I, Ohlund C, Eek C, Wallin L, Peterson LE, Fordyce WE, Nachemson AL: The effect of graded activity on patients with subacute low back pain: a randomized prospective clinical study with an operantconditioning behavioral approach. Phys Ther 1992, 72:279-290. discussion 291-273.

28. Smeets RJ, Vlaeyen JW, Hidding A, Kester AD, van der Heijden GJ, Knottnerus JA: Chronic low back pain: physical training, graded activity with problem solving training, or both? The one-year post-treatment results of a randomized controlled trial. Pain 2008, 134:263-276.

29. van der Giessen RN, Speksnijder CM, Helders PJ: The effectiveness of graded activity in patients with non-specific low-back pain: a systematic review. Disabil Rehabil 2012, 34:1070-1076.

30. Shephard RJ: PAR-Q, Canadian home fitness test and exercise screening alternatives. Sports Med 1988, 5:185-195.

31. Schulz KF, Chalmers I, Hayes RJ, Altman DG: Empirical evidence of bias. Dimensions of methodological quality associated with estimates of treatment effects in controlled trials. JAMA 1995, 273:408-412.
32. Ciconelli RM, Feraz MB, SAntos W: Tradução para a língua portuguesa e validação do questionário genérico de avaliação de qualidade de vida SF-36. Rev Bras Reumatol 1999, 39:143-149.

33. Menezes Costa Lda C, Maher CG, McAuley JH, Hancock MJ, de Melo Oliveira W, Azevedo DC, Freitas Pozzi LM, Pereira AR, Costa LO: The BrazilianPortuguese versions of the McGill pain questionnaire were reproducible, valid, and responsive in patients with musculoskeletal pain. J Clin Epidemiol 2011, 64:903-912.

34. Florindo AA, Latore MRDO: Validação e Reprodutibilidade do questionátio de Baecke de avaliação física habitual em homens adultos. Rev Bras Med Esporte 2003, 9:121-128.

35. Varoli FK, Pedrazzi V: Adapted version of the McGill Pain Questionnaire to Brazilian Portuguese. Braz Dent J 2006, 17:328-335.

36. Costa LO, Maher CG, Latimer J, Ferreira PH, Pozzi GC, Ribeiro RN: Psychometric characteristics of the Brazilian-Portuguese versions of the functional rating index and the roland Morris disability questionnaire. Spine (Phila Pa 1976) 2007, 32:1902-1907.

37. Siqueira FB, Texeira-Salmela LF, Magalhães LC: Análise das propriedades psicométricas da versão brasileira da Escala Tampa de Cinesiofobia. Acta Ortop Bras 2007, 15:19-24.

38. de Souza FS, Marinho Cda S, Siqueira FB, Maher CG, Costa LO: Psychometric testing confirms that the Brazilian-Portuguese adaptations, the original versions of the fear-avoidance beliefs questionnaire, and the Tampa scale of kinesiophobia have similar measurement properties. Spine (Phila Pa 1976) 2008, 33:1028-1033.

39. Ocarino JM, Gonçalves GGP, Vaz DV, Cabral AAV, Porto JV, Silva MT: Correlation between a functional performance questionnaire and physical capability tests among patients with low back pain. Rev Bras Fisioter 2009, 13:343-349.

40. Navega MT, Aveiro MC, Oishi J: The influence of a physical exercise program on the quality of life in osteoporotic women. Fisioter mov 2006 19:25-32.

41. Macedo LG, Latimer J, Maher CG, Hodges PW, Nicholas M, Tonkin L, McAuley JH, Stafford R: Motor control or graded activity exercises for chronic low back pain? A randomised controlled trial. BMC Musculoskelet Disord 2008, 9:65.

42. Smeets RJ, Vlaeyen JW, Hidding A, Kester AD, van der Heijden GJ, van Geel $A C$, Knottnerus JA: Active rehabilitation for chronic low back pain: cognitive-behavioral, physical, or both? First direct post-treatment results from a randomized controlled trial [ISRCTN22714229]. BMC Musculoskelet Disord 2006, 7:5.

43. MCARDLE ea: Fisiologia do Treinamento físico. São Paulo: Guanabara Koogan; 1997.

44. Altman DG: Practical statistics for medical research. London: Chapman and Hall; 1991

\section{doi:10.1186/1471-2474-14-36}

Cite this article as: Magalhaes et al:: Efficacy of graded activity versus supervised exercises in patients with chronic non-specific low back pain: protocol of a randomised controlled trial. BMC Musculoskeletal Disorders 2013 14:36.

\section{Submit your next manuscript to BioMed Central and take full advantage of:}

- Convenient online submission

- Thorough peer review

- No space constraints or color figure charges

- Immediate publication on acceptance

- Inclusion in PubMed, CAS, Scopus and Google Scholar

- Research which is freely available for redistribution 